\section{Why dentists should take a greater interest in sex and gender}

\author{
L. Doyal ${ }^{1}$ and S. Naidoo ${ }^{2}$
}

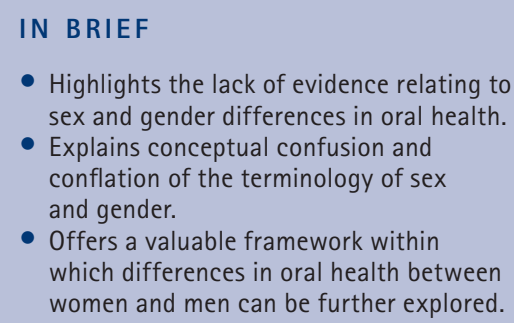

This brief review highlights the lack of evidence relating to sex and gender differences in oral health as well as the widespread conceptual confusion and conflation that often underlies them. A broader biomedical understanding of these issues will offer a valuable framework within which differences in oral health between women and men can be further explored. This in turn would facilitate the development of the evidence base necessary to optimise the efficacy of dental practice in meeting the needs of both women and men patients.

\section{INTRODUCTION}

The last decade has seen a growing interest in the links between sex, gender and health..$^{1-3}$ This has been reflected in a range of policy initiatives and also in the practice of medical research. Much of this activity was initiated by those campaigning on behalf of women. However, many international organisations and professional associations have now taken up similar concerns. They have recognised the importance of these issues not just from the perspective of equity but also as a prerequisite for more effective care.

As a result, there is now a sizeable evidence base on differences in patterns of morbidity and mortality between women and men. However, these issues have so far received very little attention in the context of research and practice in oral health. This paper will argue that these gaps need to be filled.

It will begin with a clarification of meaning of the terms 'sex' and 'gender'. This will be followed by a brief review of what is known (and not known) about the impact of each on oral health and on

"Emeritus Professor of Health and Social Care, School for Policy Studies, University of Bristol, 8 Priory Road, Bristol, BS8 1TZ; ${ }^{2}$ Professor and Principal Specialist, Department of Community Oral Health, University of the Western Cape, Tygerberg, Cape Town, South Africa ${ }^{*}$ Correspondence to: Professor Lesley Doyal Email: I.doyal@bristol.ac.uk

\section{Refereed Pape}

Accepted 8 July 2010

DOI: $10.1038 /$ sj.bdj.2010.883

${ }^{\bullet}$ British Dental Journal 2010; 209: 335-337 dental care. The interaction of the two will then be highlighted through the examples of pain and dental caries. The final section will summarise the reasons why dentists and other specialists in oral health should take these issues more seriously.

\section{DEFINING SEX AND GENDER}

The terms 'sex 'and 'gender' are beginning to appear more frequently in the biomedical literature. However, there is often confusion about their significance in both research and practice. This is especially evident in the fields of dentistry and oral health. Too often the terms are used interchangeably, with 'gender 'assumed to be nothing more than a 'politically correct' term for 'sex'. However there is an important conceptual distinction to be made between them. ${ }^{1}$

In common sense thinking and in the discourse of scientific research it is innate biological differences between women and men that have received most attention. This exploration of sex differences has traditionally focused on issues related to procreation (such as obstetric problems) or disorders of sex-specific organs (including cancers of the cervix or prostate). However, the last decade has seen an explosion of research on wider sex differences. These go beyond reproduction to include a range of variations in the functioning of male and female bodies. ${ }^{4}$

At the same time there has been a growing recognition that the health of both women and men is influenced by gender which is social rather than biological in origin. All societies are divided by what is often called the 'fault line' of gender. This means that males and females are treated differently. This may include being expected to take on gender-specific duties and responsibilities in return for unequal compensation. The nature and degree of these divisions will vary between societies and communities but they are always significant in shaping the health of individual women and men.

Hence it will be necessary to explore the influences of sex and gender as well as the interactions between them in order to optimise the oral health of women and of men across a range of settings.

\section{IMPLICATIONS OF BIOLOGICAL SEX ON HEALTH: REPRODUCTION AND BEYOND}

Recent research has shown that genetic, hormonal and metabolic differences all create variations in male and female experiences of health and illness. ${ }^{4}$ It is well known, for example, that biological factors are partly responsible for the fact that heart disease occurs at a younger age among males. Men are also inherently more susceptible than women to a range of infectious diseases but women are more susceptible to most autoimmune problems.

Thus far these wider biological differences have received very little attention in the context of oral health. Instead the 
main focus has been on women and reproduction as recent studies of the US dental curriculum have confirmed. ${ }^{5}$ Moreover a frequently cited review of sex differences in morbidity and mortality picked out oral health in particular as an area in which very little information was available. ${ }^{4}$ It called for more research linking sex differences in oral health to wider trends in health and illness.

Recent years have seen the slow growth of studies exploring these themes. ${ }^{6}$ There is evidence for example, of differences in periodontal health in women and men that are related to both heart disease and diabetes. ${ }^{7}$ There is also some evidence that men are more likely than women to experience oral health problems as part of HIV and AIDS. ${ }^{8}$ Temporomandibular disorders appear to be significantly more common in women but the reasons for this are not clear. ${ }^{9}$

The impact of biological differences on the oral health of women and men therefore requires much greater attention. However, this needs to be accompanied by a clearer understanding of the influence of social gender.

\section{IMPLICATIONS OF GENDER FOR HEALTH}

Economic, cultural and social differences between women and men can influence their health status in a number of different ways. ${ }^{2}$ The marked differences in their daily lives can affect their exposure to particular health hazards and also their risk of particular mental and physical disorders. It will shape their access to resources (including income, power and time) for promoting health. It also influences when and where individuals seek help and what quality of care they receive.

Much research on the impact of gender on the health of women has focused on their relative poverty. ${ }^{10}$ From a global perspective it is clear that women are more likely than men to be lacking the basic resources for a healthy life. This reflects wider cultural beliefs about their social worth and the reflection of these in structural discrimination. In most parts of the world women face gendered obstacles to education and employment as well as lower (or no) wages. A significant body of evidence indicates that this can be linked to a wide range of both physical and mental health problems.
Again, very little is known about how these issues play out in the context of oral health. However the World Report on Oral Health gives some indication of possible links. ${ }^{11}$ Though it makes no explicit reference to gender differences the report does focus on the links between poor oral health and lower socio-economic status. Hence there are sound reasons for assuming that women's greater poverty is likely to be a significant risk to their oral health.

of course gender also affects the health of men, though this has so far received less attention. Being male bestows certain advantages from the perspective of social status and power. However, the expectations associated with masculinity can also pose a threat to men's health. ${ }^{12}$ We know, for example, that men are more likely than women to die as a result of hazards at work. They are also more likely to be involved in episodes of violence and in risk taking and health damaging behaviour of various kinds which are seen in many cultures as 'evidence' of masculinity.

Again the links with oral health have not been formally spelled out but there are obvious connections between 'masculine behaviour' and dental problems. These include excessive alcohol consumption and smoking, both of which have been shown to be potentially damaging. Though these harmful effects have been identified in the dental literature they have not been presented through the perspective of gender. Similarly it has been noted that men are more likely than women to be damaged by dental trauma but again this has not been conceptually linked to the gendered nature of personal violence or road traffic accidents.

\section{GENDER DIFFERENCES IN HEALTHCARE}

There is an extensive literature on gender and medical services in general with women apparently using services more than men. ${ }^{2}$ Again the data on dentistry are rather limited but women also appear to be more likely to visit dentists regularly and to adhere to recommended regimes. ${ }^{13,14}$ However, it is important to note that most of this research has been carried out in developed countries and more work is needed to determine patterns of use among the poorest communities.
One exception to this pattern is to be found in a excellent study exploring the implications of gender on oral health and health care in two deprived communities in Guatemala. ${ }^{15}$ Despite the very high cost it was young women who were most likely to have their teeth 'pulled' in order (where possible) to replace them with a 'plate'. This reflected their concern with appearance as well as their fear of future pain. It was also seen by them and their families as an investment to ensure the best possible marriage. Men on the other hand rarely sought help, often suffering extreme pain in order to demonstrate their stoicism and also to save money.

\section{INTERACTIONS BETWEEN SEX AND GENDER}

We have seen the importance of making a conceptual distinction between biological sex and social gender in understanding both oral health and dental care. However, their effects may well be difficult to disentangle in specific contexts. We can illustrate this through two examples: experiences of pain and the causation of dental caries.

There is now a huge literature on the topic of pain which raises key methodological issues in making sense of the impact of sex and gender. ${ }^{16-19}$ However, few of these have been carried out in the context of dentistry despite its obvious relevance for practice.

There seems to be a general consensus that women either experience or express more pain than men in the same circumstances. But there is continuing debate about what this means. Are women in fact experiencing more pain or are they simply more willing/able to express it? If women do experience more pain is this due to differences in aspects of biological functioning such as liver metabolism, immune responses or hormonal changes? Or is it simply that women are allowed to be 'weak' while men are expected to appear 'strong'?

Many studies have shown that caries rates are higher in women than in men. ${ }^{20}$ These variations have traditionally been assumed to be biological in origin but recent work has seen it as multi-factorial with both sex and gender involved. The biological factors identified have included salivary composition 
and flow rate, hormonal fluctuations in pregnancy and earlier tooth eruption among females. Among the social aspects recognised as requiring further investigation are gender differences in diet and eating patterns as well as wider dimensions of inequality between women and men. ${ }^{20,21}$

\section{CONCLUSION}

This brief review has highlighted the lack of evidence relating to sex and gender differences in oral health as well as highlighting the conceptual confusion that often underlies them. The current growth in wider biomedical understanding of these issues offers a valuable framework within which differences in oral health between women and men can be further explored. This in turn would facilitate the development of the evidence base necessary to optimise the efficacy of dental practice in meeting the needs of both women and men.
1. Doyal L. Sex, gender and health: the need for a new approach. BMJ 2001; 323: 1061-1063.

2. Payne $\mathrm{S}$. The health of women and men. Cambridge: Polity Press, 2006.

3. Krieger N. Gender, sexes and health: what are the connections - and why does it matter? Int J Epidemiol 2003; 32: 652-657.

4. Wizemann T, Pardue M. Explaining the biological contribution to human health: does sex matter? Washington DC: National Academy Press, 2001.

5. Sinkford J, Valachovic R, Harrison S. Women's oral health: the evolving science. J Dent Educ 2008; 72: 131-134.

6. Slavkin H. Distinguishing Mars from Venus: emergence of gender biology differences in oral health and systemic disease. Compend Contin Educ Dent 2002; 23(10 Suppl): 29-31.

7. Desvarieux M, Schwahn C, Völzke H et al. Gender differences in the relationship between periodontal disease, tooth loss and atherosclerosis. Stroke 2004; 35: 2029-2035.

8. Obuekwe O, Onunu A. Gender and oral manifestations of HIV infection among adult Nigerians. Afr J Reprod Health 2006; 10: 81-89.

9. Phillips J M, Gatchel R J, Wesley A L, Ellis E III. Clinical implications of sex in acute temporomandibular disorders. J Am Dent Assoc 2001; 132: 49-57.

10. Doyal L. What makes women sick: gender and the political economy of health. London: Macmillan, 1995.

11. Petersen $P$, Bourgeois D, Ogawa H, Estupinan-Day $S$, Nfaiaye $C$. The global burden of oral diseases and risks to oral health. Bull World Health Organ 2005; 89: 661-669.
12. Robertson S. Understanding men and health: masculinities, identity and well-being. Maidenhead: Open University Press, 2007.

13. Tada A, Nobuhiro H. Sexual differences in oral health behaviour and factors associated with oral health behaviour in Japanese young adults. Public Health 2004; 118: 104-109.

14. Berta P C, Staehelin K, Dratva J, Kemp Stutz E. Female gender is associated with dental care and dental hygiene but not with complete dentition in the Swiss adult population. J Public Health 2007; 15: 361-367.

15. Hunter J M, Arbona SI. The tooth as a marker of developing world quality of life: a field study in Guatemala. Soc Sci Med 2007; 41: 1217-1240.

16. Greenspan J D, Craft R M, LeResche L et al. Consensus Working Group of the Sex, Gender, and Pain SIG of the IASP. Studying sex and gender differences in pain and analgesia: a consensus report. Pain 2007; 132: S26-S45.

17. Richardson J, Holdcroft A. Gender differences and pain medication. Women's Health (Lond Eng) 2009; 5: 79-90.

18. Fillingim $R$, King $C D$, Ribeiro-Dasilva $M C$ et al. Sex, gender and pain: a review of recent clinical and experimental findings J Pain 2009; 10: 447-485.

19. Wiesenfeld-Hallin Z. Sex differences in pain perception. Gend Med 2005; 2: 137-145.

20. Ferraro $M$, Vieira A. Explaining gender differences in caries: a multifactorial approach to a multifactorial disease. Int J Dent 2010; 2010: 649643.

21. Lukacs J. Fertility and agriculture accentuate sex differences in dental caries rates (2008). Curr Anthropol 2005; 49: 901-914. 